\title{
Effects of High Hydrostatic Pressure on Escherichia coli Ultrastructure, Membrane Integrity and Molecular Composition as Assessed by FTIR Spectroscopy and Microscopic Imaging Techniques
}

\author{
María Prieto-Calvo ${ }^{1}$, Miguel Prieto ${ }^{1,2}$, Mercedes López ${ }^{2}$ and Avelino Alvarez-Ordóñez ${ }^{3, *}$ \\ 1 Institute of Food Science and Technology, University of León, León 24071, Spain; \\ E-Mails: mpriec01@estudiantes.unileon.es (M.-P.C.); miguel.prieto@unileon.es (M.P.) \\ 2 Department of Food Hygiene and Technology, University of León, León 24071, Spain; \\ E-Mail:mmlopf@unileon.es \\ 3 Teagasc Food Research Centre, Moorepark, Fermoy, Co. Cork, Ireland \\ * Author to whom correspondence should be addressed; E-Mail: avelino.alvarez-ordonez@teagasc.ie; \\ Tel.: +353-25-42270.
}

External Editor: Christian Huck

Received: 8 October 2014; in revised form: 27 November 2014 / Accepted: 9 December 2014 / Published: 18 December 2014

\begin{abstract}
High hydrostatic pressure (HHP) is a novel food processing technology that is considered as an attractive alternative to conventional heat treatments for the preservation of foods, due to its lethal effects on pathogenic and spoilage microorganisms, while causing minor effects on food quality and sensorial attributes. This study is aimed at investigating how HHP treatments at varying intensities in the range 50-900 MPa affect the viability, membrane integrity, ultrastructure and molecular composition of Escherichia coli. Results of membrane integrity tests (measurement of cellular leakage and monitoring of propidium iodide uptake through fluorescence microscopy) and ultrastructural observations by transmission electron microscopy demonstrated that HHP gave rise to cellular enlargement, membrane damage or detachment, DNA and protein denaturation and loss of intracellular contents. Fourier-transform infrared (FTIR) spectroscopy analyses evidenced minor changes in molecular composition in response to high pressures, which were mostly observed on the spectral region $\mathrm{w}_{4}\left(1200-900 \mathrm{~cm}^{-1}\right)$, mainly informative of carbohydrates and polysaccharides of the cell wall. These findings suggest that exposure of $E$. coli cells to HHP causes alterations in their physical integrity while producing minor modifications in
\end{abstract}


biochemical cellular composition. The current study increases the knowledge on the mechanisms of $E$. coli inactivation by HHP and provides valuable information for the design of more effective food preservation regimes based on the integration of mild HHP in combination with other food preservation strategies into a multi-target hurdle technology approach.

Keywords: high hydrostatic pressure; Escherichia coli; FTIR spectroscopy; cell imaging; inactivation mechanism; food safety

\section{Introduction}

High hydrostatic pressure (HHP) is a food processing technology used to maintain the quality attributes of fresh foods, while extending their shelf life through the inactivation of pathogenic and spoilage microorganisms, as well as of endogenous enzymes. In fact, HHP has been proposed as an alternative to thermal processing due to the less detrimental effects it shows on food quality and organoleptic properties [1-3].

Great research efforts have been made in recent years to evaluate the safety of HHP-treated foods by studying the inactivation kinetics by HHP of pathogenic microorganisms in food and food models [4]. The foodborne pathogens, Staphylococcus aureus, Listeria monocytogenes, Salmonella spp. and verocytotoxigenic Escherichia coli (VTEC), are among the bacterial species most extensively studied with this aim [1]. VTEC, characterized by the production of Shiga toxins, are important foodborne pathogens in the European Union, with 5,671 reported human cases in 2012, which yields a community incidence rate of 1.15 per 100,000 population [5]. Some strains of VTEC are among the most pressure-resistant vegetative cells described to date [6,7]. However, wide variations among E. coli strains in HHP resistance have been described, with some strains being inactivated by pressures as low as $200 \mathrm{MPa}$, whereas others can survive exposures to $600 \mathrm{MPa}$ [6-9].

Despite much effort in recent years, the main cellular targets and the mechanisms of bacterial killing by HHP have not yet been fully identified [10]. Knowledge on the mechanisms of bacterial inactivation by HHP is, however, essential to define appropriate strategies to guarantee food safety and to optimize process implementation. The cell envelopes have been suggested to be a major target of HHP treatments. Thus, loss of physical integrity of the outer and inner membranes has been shown to occur by means of the increased uptake of fluorescent probes that do not penetrate intact envelopes, the lack of osmotic responsiveness or the loss of intracellular material [11-14]. Nevertheless, other cellular components, such as ribosomes and cytoplasmic and membrane proteins have been also shown to be affected by HHP treatments [15-18], and protein denaturation and induction of oxidative stress have been reported to occur after exposure to HHP [19]. Transmission electron microscopy (TEM) and scanning electron microscopy (SEM) offer the possibility of identifying the cellular structures affected by HHP. For instance, some authors have described by TEM the presence of enlarged fibrillar regions and amorphous compacted regions, corresponding to denaturated DNA and cytoplasmic proteins. In addition, cells with a rougher surface and blister-like protrusions have been observed with SEM [20-22]. Fourier transform infrared (FTIR) spectroscopy is a vibrational spectroscopic technique 
that enables the biochemical signatures from microbiological structures to be extracted and analyzed and, therefore, has recently emerged as a useful methodology for the study of the mechanisms of sublethal injury and death induction resulting from bacterial exposure to food processing technologies, antimicrobial compounds and adverse environmental conditions [23,24]. Since FTIR spectra provide information on the biochemical composition of the main cellular constituents, the study of HHP-treated cells by FTIR spectroscopy may assist the identification of the cellular targets that result in being damaged after exposure to this food processing technology.

This study aimed to determine the morphological and physico-chemical changes occurring in cells of $E$. coli strains after HHP treatments of different intensities. For this purpose, the uptake of the fluorescent probe, propidium iodide (PI), and the loss of intracellular contents were used as indicators of membrane damage, while morphological alterations were analyzed by TEM and global changes in cellular biochemical features were assessed by FTIR spectroscopy.

\section{Results and Discussion}

\subsection{Results}

Stationary-phase cultures of Escherichia coli E218/02 and Escherichia coli C-600 were exposed to different pressure-time combinations (50 MPa, 24 h; $300 \mathrm{MPa}, 5 \mathrm{~min}$; $600 \mathrm{MPa}, 5 \mathrm{~min}$; and $900 \mathrm{MPa}$, $5 \mathrm{~min}$ ). Whereas HHP treatments at $50 \mathrm{MPa}$ for $24 \mathrm{~h}$ did not give rise to significant reductions in the bacterial population, exposure to $300 \mathrm{MPa}$ for $5 \mathrm{~min}$ resulted in the inactivation of 4.5 and $4.7 \mathrm{log}$ cycles for E. coli $\mathrm{E} 218 / 02$ and E. coli C-600, respectively, and treatment at $600 \mathrm{MPa}$ for 5 min gave rise to a 6.8 and $7.3 \log$ reduction, respectively (Figure 1A). No survivors were found after HHP treatments at $900 \mathrm{MPa}$ for $5 \mathrm{~min}$ ( $>8 \mathrm{log}$ cycles of inactivation). No significant differences in HHP resistance were observed between both $E$. coli strains at the pressure-time combinations assayed.

Figure 1. (A) Inactivation of Escherichia coli E218/02 (black bars) and Escherichia coli C-600 (white bars) by high hydrostatic pressure (HHP) (log CFU/mL); (B) OD260 of cell-free filtrates of Escherichia coli E218/02 (black bars) and Escherichia coli C-600 (white bars) untreated or treated with HHP at $300 \mathrm{MPa}$ and $600 \mathrm{MPa}$; (C) $\mathrm{OD}_{280}$ of cell-free filtrates of Escherichia coli E218/02 (black bars) and Escherichia coli C-600 (white bars) untreated or treated with $\mathrm{HHP}$ at $300 \mathrm{MPa}$ and $600 \mathrm{MPa}$. Results are shown as the average \pm standard deviation.

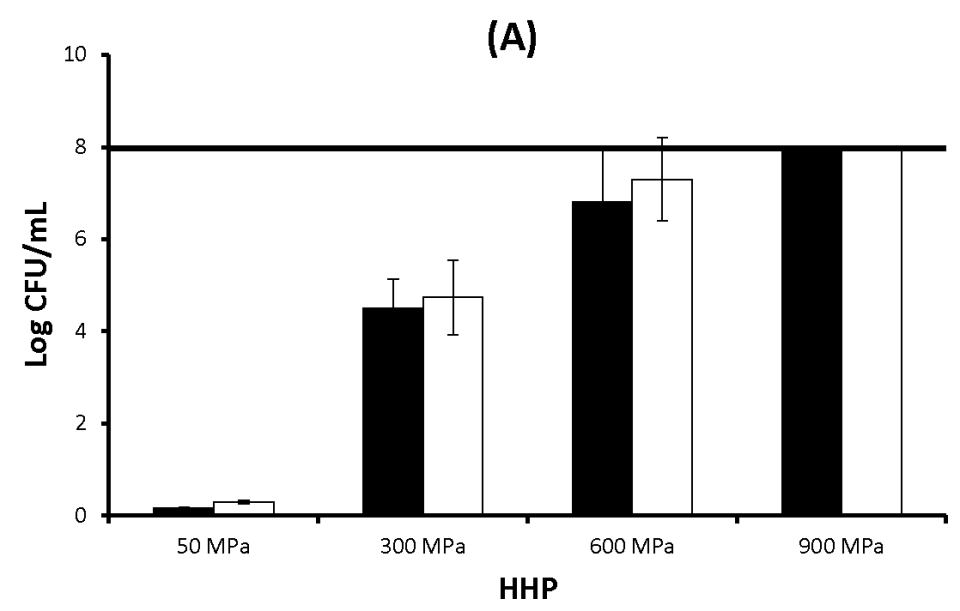


Figure 1. Cont.

(B)

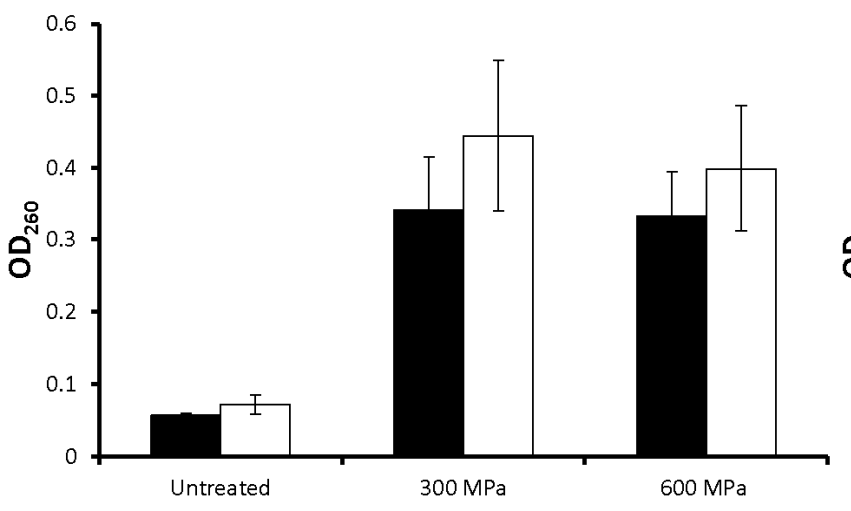

(C)

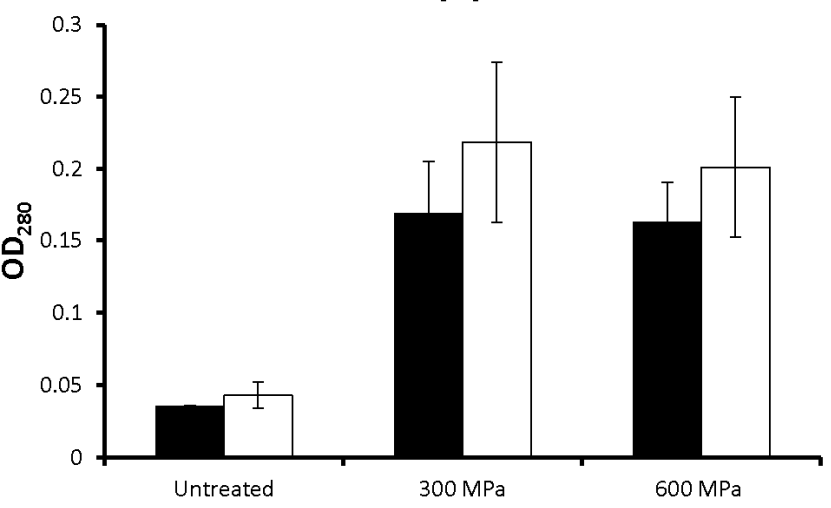

The leakage of intracellular nucleic acids and proteins after HHP treatment at $300 \mathrm{MPa}$ for $5 \mathrm{~min}$ and $600 \mathrm{MPa}$ for $5 \mathrm{~min}$ was assessed by monitoring the optical density at $260 \mathrm{~nm}\left(\mathrm{OD}_{260}\right)$ and $280 \mathrm{~nm}$ $\left(\mathrm{OD}_{280}\right)$ of cell-free filtrates from untreated and treated samples (Figure 1B,C). HHP treatment at $300 \mathrm{MPa}$ caused a significant increase in both $\mathrm{OD}_{260}$ and $\mathrm{OD}_{280}$ of a similar magnitude for both $E$. coli strains. A further increase in pressure intensity (600 MPa) did not result in a further increase in OD260 and $\mathrm{OD}_{280}$ values, which were similar to those observed for cells treated at $300 \mathrm{MPa}$. No significant differences in $\mathrm{OD}_{260}$ and $\mathrm{OD}_{280}$ values were observed between E. coli E218/02 and E. coli C-600 at any of the treatment conditions.

Membrane integrity was also evaluated by following through fluorescence microscopy the intake of propidium iodide (PI) by untreated and HHP-treated populations (Figure 2). PI enters the cell when membrane integrity is compromised and binds to intracellular nucleic acids. Whereas less than $10 \%$ of untreated cells were stained when exposed to PI, the vast majority of HHP-treated cells (300 and $600 \mathrm{MPa}$ for $5 \mathrm{~min}$ ) were PI stained, which indicates the presence of HHP-induced damage in bacterial membranes.

The effects of HHP treatment on the ultrastructure of E. coli E218/02 and E. coli C-600 were assessed by using transmission electron microscopy (Figure 3). Untreated samples consisted mainly of single or dividing cells with a centrally-situated genome surrounded by the cytoplasmic area with tightly-packed ribosomes. Cell membranes and walls of these untreated cells were clearly distinguished. Cells within HHP-treated samples showed an altered appearance, with enlarged sizes and loss of the general cellular shape. Disorganization of the genome area was apparent, with the presence of blank spaces in the cytoplasm and condensation of the cytoplasmic material in amorphous compacted regions. Bacterial membranes presented winding shapes and sometimes were disrupted or detached from the cytoplasmic content. Similar ultrastructural alterations were observed for both E. coli strains at the two HHP treatment intensities (300 and $600 \mathrm{MPa}$ for $5 \mathrm{~min}$ ).

The changes in the molecular composition after HHP treatment were determined by using FTIR spectroscopy (Figure 4). Although no major modifications were visibly observed in the untransformed spectra, when the spectra were further processed, the chemically-based spectral differences were amplified and some minor modifications could be observed. Transformation of spectra included normalization, which balanced the differences in path strength, smoothing, which eliminated the instrumental noise, and second derivatization, which separated absorption bands, removed baseline shifts and increased spectral resolution. Measurement of the reproducibility of spectra by using the Pearson coefficient 
showed that low variability among replicates existed. Spectral windows w1 $(0.97 ; 0.82)$ and w4 $(3.21$; 3.59) showed the lowest differentiation indexes $(D I)$ and, consequently, the highest reproducibility, which demonstrates a good standardization of growth conditions and preparation of samples.

Figure 2. Uptake of propidium iodide by cells of Escherichia coli E218/02 (A) and Escherichia coli C-600 (B) untreated or treated with HHP at $300 \mathrm{MPa}$ and $600 \mathrm{MPa}$ followed by fluorescence microscopy.

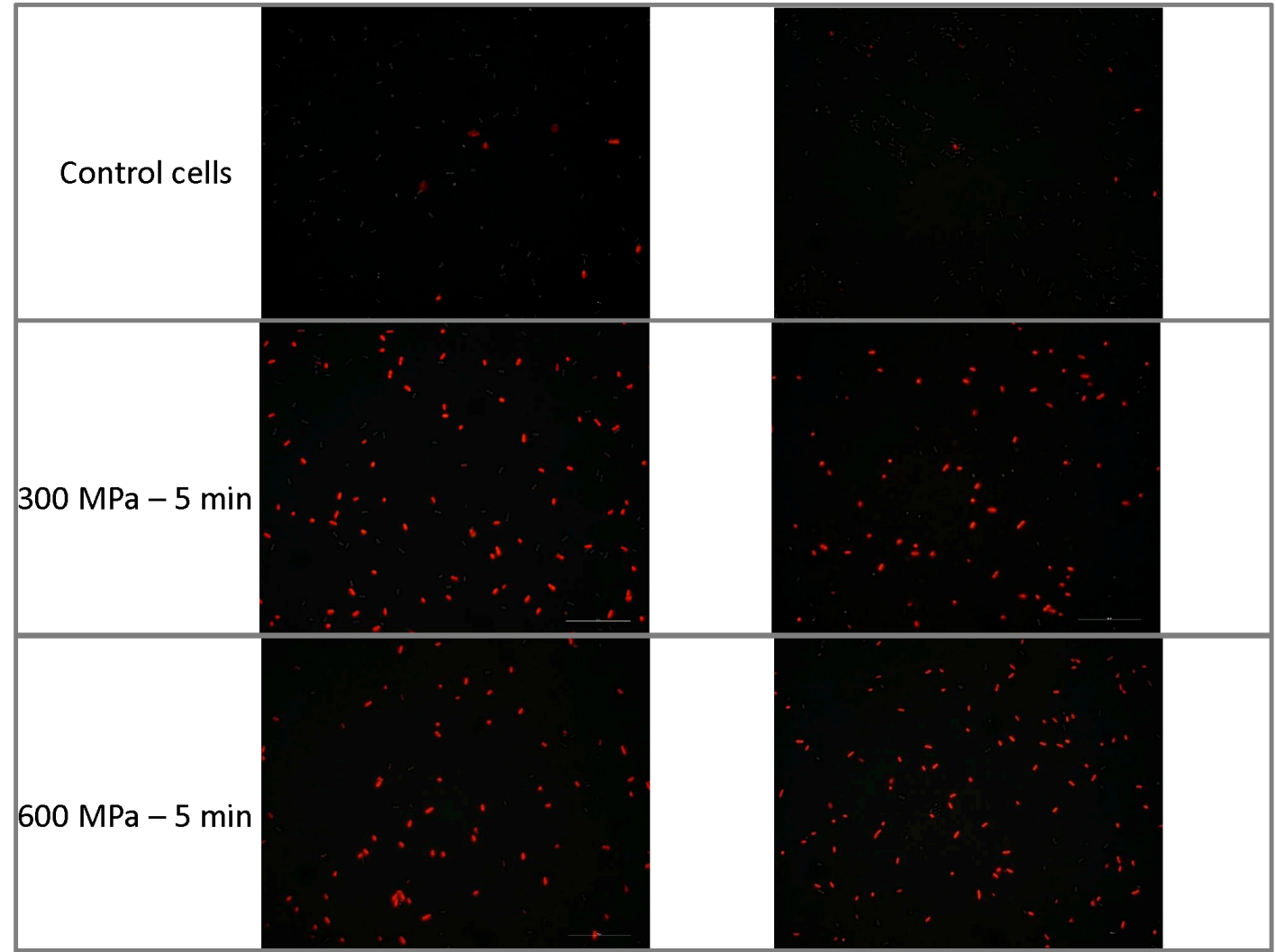

(A)

(B)

Figure 3. Representative electron micrograph sections of cells of Escherichia coli E218/02 (A) and Escherichia coli C-600 (B) untreated or treated with $\mathrm{HHP}$ at $300 \mathrm{MPa}$ and $600 \mathrm{MPa}$. a: cytoplasmic membrane; b: cell wall; c: enlarged cell; d: disorganization of the genome area; e: condensation of cytoplasmic material in amorphous regions; f: membrane with winding shape; g: detached membrane.

Control cells

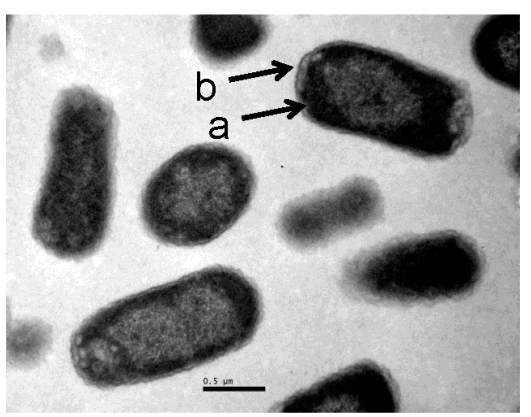

$300 \mathrm{MPa}-5 \mathrm{~min}$

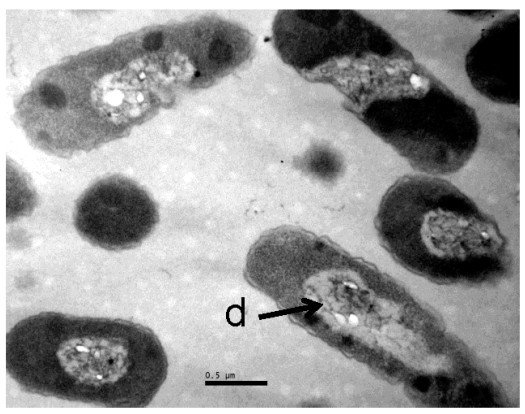

(A)
$600 \mathrm{MPa}-5 \mathrm{~min}$

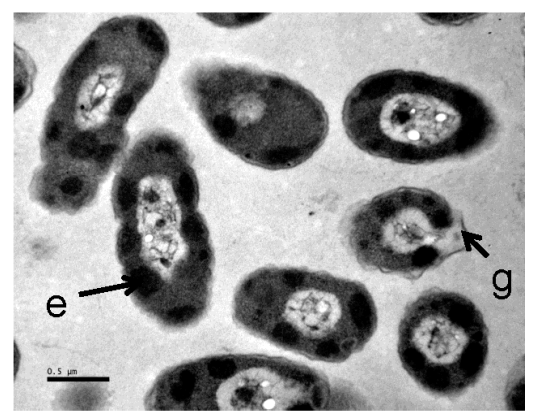


Figure 3. Cont.

Control cells

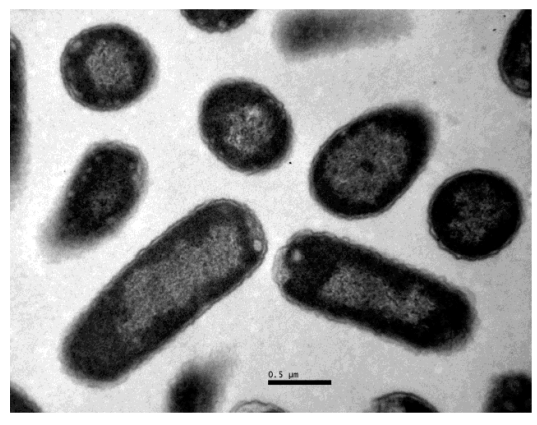

$300 \mathrm{MPa}-5 \mathrm{~min}$

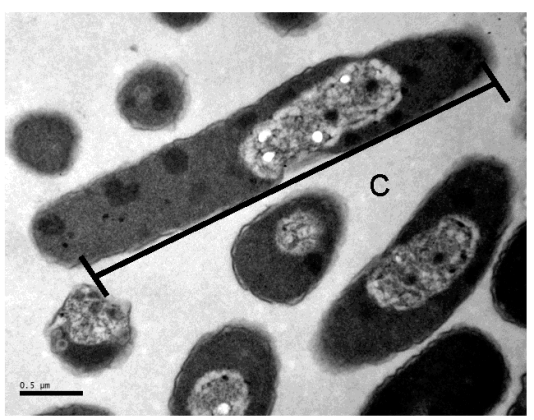

$600 \mathrm{MPa}-5 \mathrm{~min}$

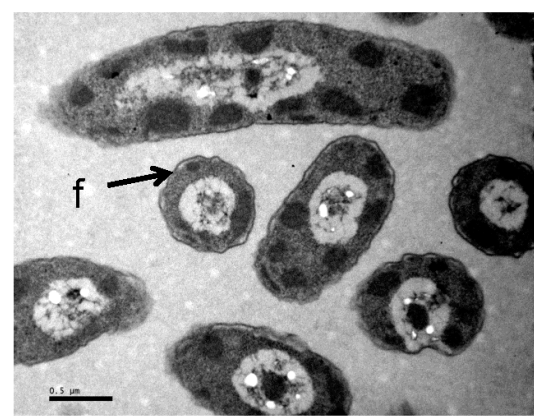

(B)

Figure 4. (A) Dendrogram obtained from $\mathrm{w}_{4}\left(1200\right.$ to $\left.900 \mathrm{~cm}^{-1}\right)$ spectral region data of two replicates (rep 1; rep 2) of strains Escherichia coli E218/02 (Strain number 2, Str 2) and Escherichia coli C-600 (Strain number 9, Str 9) untreated or HHP-treated cells, with cluster analysis performed with the Pearson product moment correlation coefficient and by the Ward algorithm method [25]; (B) untransformed FTIR spectra (w3, w4 and w5 spectral ranges,) of E. coli E218/02 (Str 2) before and after HHP treatment at different pressures $(50,300$ and $900 \mathrm{MPa})$.

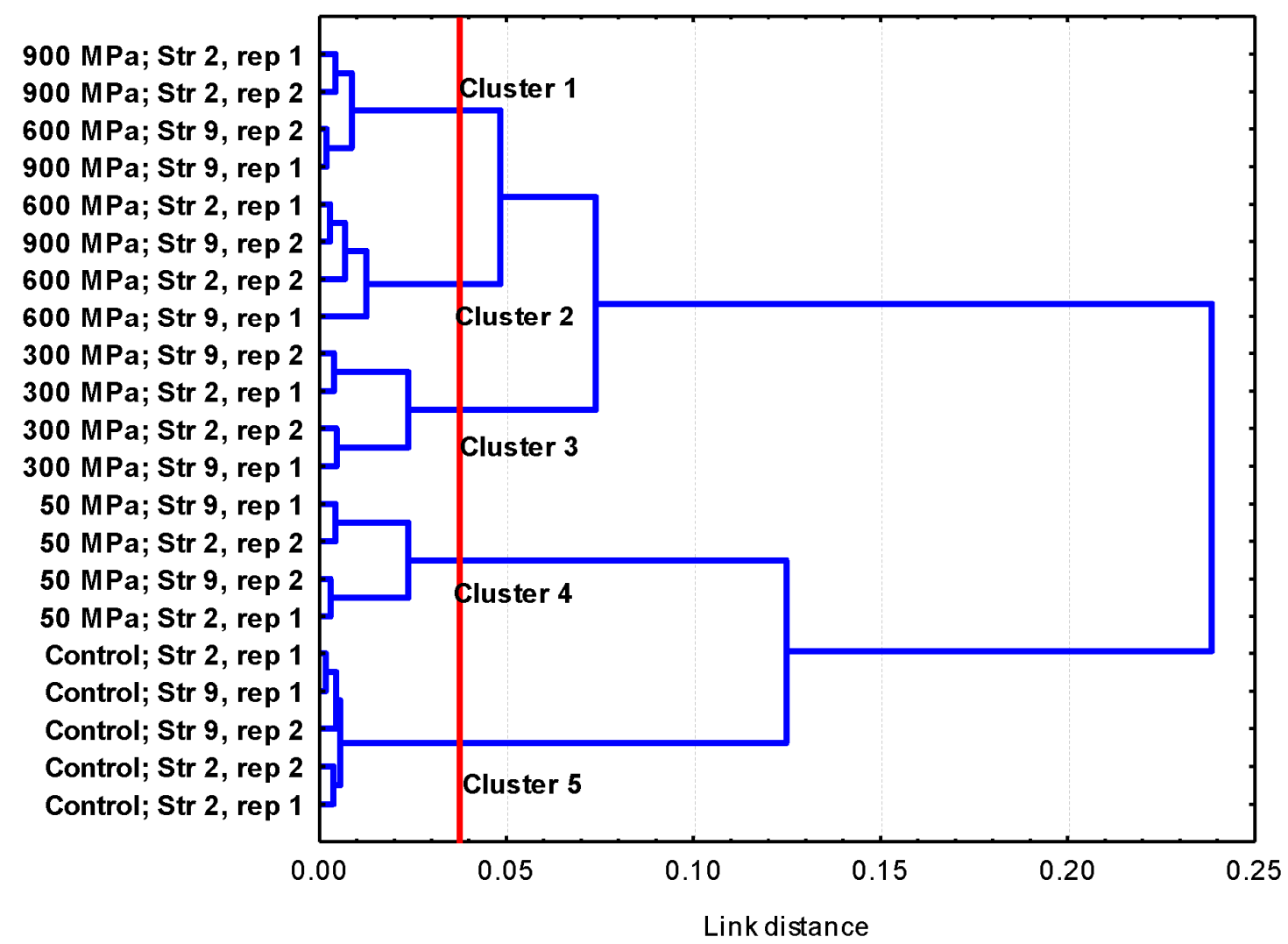

(A) 
Figure 4. Cont.

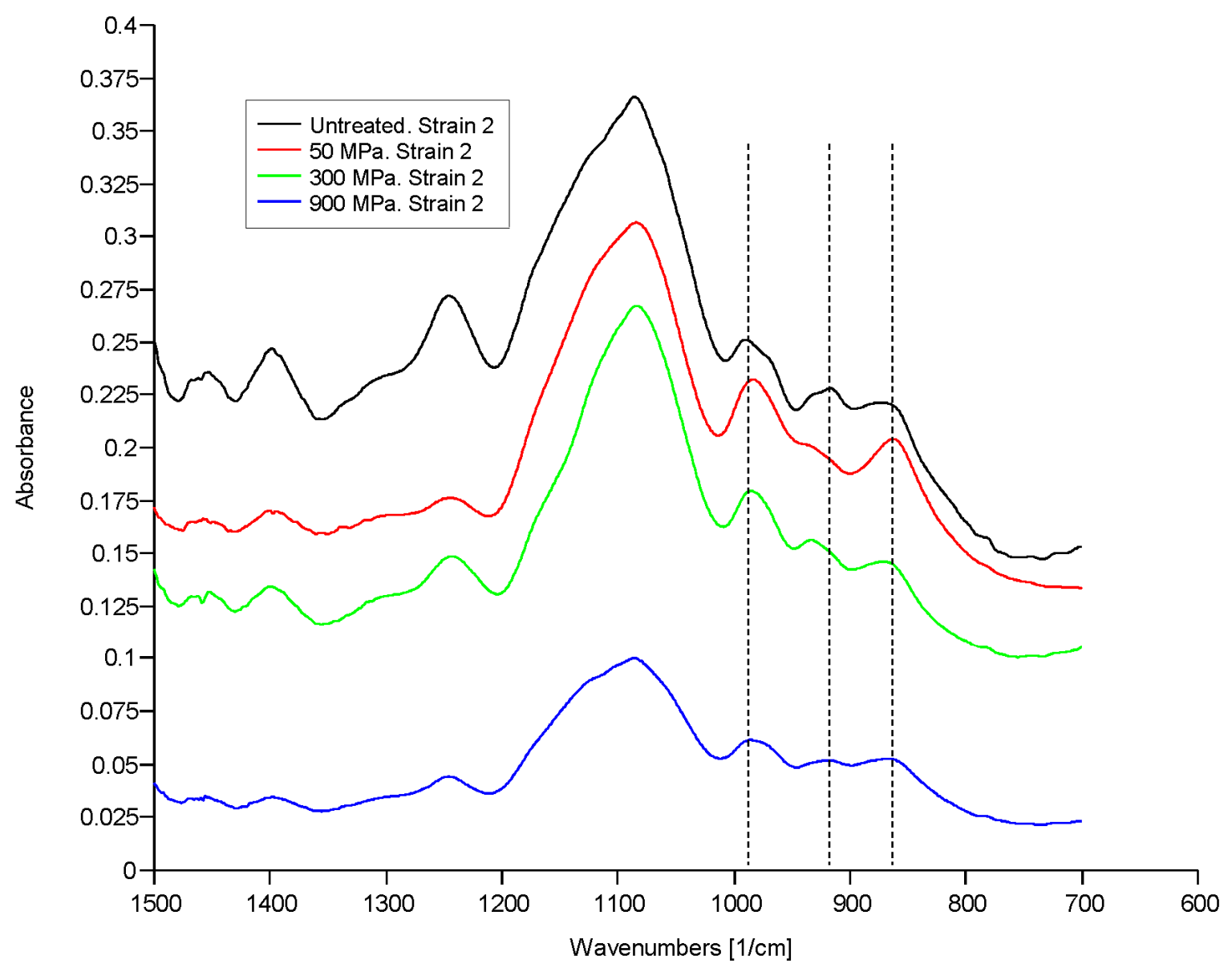

(B)

Hierarchical cluster analysis (HCA) of the second derivative spectra demonstrated that the w4 region was the most discriminant one. HCA of this spectral region divided the samples into two main groups separated with a linkage distance of 0.25 , one including untreated samples (cluster 5) and samples treated at $50 \mathrm{MPa}$ (cluster 4) and other comprising samples treated at higher pressures with lethal effects on bacterial cells (300 (cluster 3), 600 and $900 \mathrm{MPa}$ (clusters 4 and 5)) (Figure 4). No significant differences were observed for other spectral regions between untreated and HHP-treated cultures.

\subsection{Discussion}

HHP represents a novel food processing technology that can be used as an alternative to conventional heat treatments in order to guarantee microbial inactivation and food safety, while causing minor effects on the quality and sensorial attributes of foodstuffs. The current study demonstrates the efficacy of HHP treatments to inactivate VTEC. Although recent investigations have focused on the elucidation of the mechanisms of bacterial inactivation and death by HHP [11-14], no definitive conclusions have been drawn yet. Our study evaluates how HHP treatments of varying intensity alter, to a different extent, the membrane integrity, ultrastructure and molecular composition of $E$. coli cells.

The ability of high pressures to damage the bacterial membrane was assessed by measuring the release of intracellular contents and the uptake of PI (dye that enters the cell when membrane integrity 
is compromised and binds to intracellular nucleic acids) following exposure to 300 and $600 \mathrm{MPa}$ for $5 \mathrm{~min}$. Treatment at both pressure intensities gave rise to a leakage of intracellular nucleic acids and proteins, as shown by the increase in $\mathrm{OD}_{260}$ and $\mathrm{OD}_{280}$ of cell-free filtrates. This leakage of intracellular components was of a similar magnitude at 300 and $600 \mathrm{MPa}$ and suggests that HHP may cause disruption in the cellular envelopes. The vast majority of HHP-treated (300 and $600 \mathrm{MPa}$ ) cells were also stained after incubation with the dye PI, as shown by fluorescence microscopy observations. This fact evidences that their membrane was damaged, allowing for the uptake of this dye. Thus, membrane integrity tests showed that HHP treatments disrupt the cell envelopes, rendering them more permeable. These findings are in agreement with previous studies that demonstrated the occurrence of losses of physical integrity of outer and inner membranes after exposure to high pressures [11-14]. Monitoring of cellular ultrastructure allowed for the identification of alterations in the general cellular shape and structure. HHP treatment at 300 and $600 \mathrm{MPa}$ gave rise to cellular enlargement, disorganization of the genome area, condensation of the cytoplasmic material in amorphous compacted regions and bending, disruption or detachment of cellular envelopes. These morphological alterations may be linked to denaturation and release of DNA and intracellular proteins. Ultrastructural modifications reported in the current study agree with previous observations by other authors through transmission electron microscopy (TEM) and scanning electron microscopy (SEM), describing the presence of enlarged fibrillar regions and amorphous compacted regions, corresponding to denaturated DNA and cytoplasmic proteins and identifying cells with a rougher surface and blister-like protrusions following exposure to high pressures [20-22]. FTIR spectroscopy has been recently proposed as a promising technique to study the mechanisms of sublethal injury and death induction by food processing methodologies and by exposure to antimicrobial compounds and adverse environmental conditions [23,26,27]. FTIR spectroscopic measurements showed that modifications in molecular compositions following HHP treatment were small and focused at the $\mathrm{W}_{4}$ spectral region (1200 to $900 \mathrm{~cm}^{-1}$, Figure 4B), which is mainly dominated by the ring vibrations of the functional groups $\mathrm{C}-\mathrm{O}-\mathrm{C}$ and $\mathrm{C}-\mathrm{O}$ from the carbohydrates and polysaccharides of the cell wall and very specific, weak spectral patterns from ring vibrations of aromatic amino acids (tyrosine, tryptophan, phenylalanine) and nucleotides at the w5 spectral region $\left(900-850 \mathrm{~cm}^{-1}\right)$. Changes observed in these spectral regions suggest the presence of compositional or conformational alterations in some components of the external cell envelopes occurring in response to high pressures. Nonetheless, changes in FTIR spectra were minor in comparison to those previously described for $E$. coli cells exposed to a range of lethal stress conditions $[9,28,29]$.

Ultrastructural observations, membrane integrity tests and FTIR spectroscopy analysis showed that structural and physico-chemical alterations caused by HHP treatments were not dependent on the pressure intensity of the lethal HHP treatment. E. coli treatment at $300 \mathrm{MPa}$ gave rise to bacterial inactivation and significant structural and physico-chemical modifications. Treatment at $600 \mathrm{MPa}$ caused a higher level of bacterial inactivation, but did not give rise to any additional structural/compositional alterations. This suggests that bacterial damage occurs once a threshold of pressure is reached and that different levels of damage recovery could happen as a function of the treatment intensity. 


\section{Experimental Section}

\subsection{Bacterial Strains and Culture Conditions}

Two E. coli strains were used throughout this study, Escherichia coli E218/02, a VTEC O157:H7 strain originally isolated from a dry-fermented sausage involved in an outbreak in Sweden [30], and Escherichia coli C-600, a non-pathogenic laboratory strain. Cultures were maintained in cryovials at $-80{ }^{\circ} \mathrm{C}$. Bacteria were resuscitated in tubes containing $10 \mathrm{~mL}$ of brain heart infusion (BHI; Oxoid) by incubation at $37{ }^{\circ} \mathrm{C}$ for $24 \mathrm{~h}$ followed by streaking on BHI agar plates, which were then incubated under the same conditions. Precultures were prepared by transferring an isolated colony from a plate into a test tube containing $10 \mathrm{~mL}$ of sterile BHI followed by incubation at $37^{\circ} \mathrm{C}$ for $24 \mathrm{~h}$. Precultures were subsequently used to inoculate $50 \mathrm{~mL}$ of sterile BHI with approximately $10^{3}$ cells $/ \mathrm{mL}$, followed by incubation at $37{ }^{\circ} \mathrm{C}$ for $24 \mathrm{~h}$, which resulted in a stationary phase culture with approximately $10^{9}$ cells $/ \mathrm{mL}$. This culture was subsequently used for HHP treatments.

\subsection{HHP Treatments}

Aliquots of $10 \mathrm{~mL}$ of the bacterial cultures were centrifuged at $8000 \times g$ for $5 \mathrm{~min}$, and the cellular pellets were resuspended in $10 \mathrm{~mL}$ of PBS. Afterwards, suspensions $(4 \mathrm{~mL})$ were placed in heat-sealed sterile plastic pouches before pressurization. The pressure-time combinations tested were $50 \mathrm{MPa}$ for $24 \mathrm{~h}, 300 \mathrm{MPa}$ for $5 \mathrm{~min}, 600 \mathrm{MPa}$ for $5 \mathrm{~min}$ and $900 \mathrm{MPa}$ for $5 \mathrm{~min}$. HHP treatments were performed in a Model FPG 7100:9/2C Series Foodlab (Standsted Fluid Power Ltd., Essex, UK). Pressurization water and the vessel were at $12{ }^{\circ} \mathrm{C} \pm 1{ }^{\circ} \mathrm{C}$ before pressure treatment. The transmission fluid was a mixture of water and $30 \%$ propylene glycol. The adiabatic temperature increased $2-3{ }^{\circ} \mathrm{C}$ for every $100 \mathrm{MPa}$; thus, the maximum temperature range under $600 \mathrm{MPa}$ and $900 \mathrm{MPa}$ was $24-30{ }^{\circ} \mathrm{C}$ and $38-39^{\circ} \mathrm{C}$, respectively. The time taken to achieve the maximum holding pressure (900 MPa) was $50 \mathrm{~s}$, and the decompression time was about two seconds. Pouches were removed immediately after treatment and aseptically opened. Ten-fold serial dilutions were produced in sterile $0.1 \%(w / v)$ peptone solution; suitable dilutions were plated on BHI agar, and viable cells were enumerated following the incubation of plates at $37^{\circ} \mathrm{C}$ for $48 \mathrm{~h}$ (longer incubation times did not show any influence on the count).

\subsection{Membrane Integrity Tests}

\subsubsection{Assessment of Propidium Iodide (PI) Uptake}

Control untreated cultures and bacterial cultures exposed to the different pressure-time regimes were subsequently diluted in PBS to achieve a final cellular concentration of $\sim 10^{8}$ cells $/ \mathrm{mL}$. Afterwards, $1 \mu \mathrm{L}$ of PI (Molecular Probes, Life Technologies, Grand Island, NY, USA) was added, and the mix was incubated in the dark at room temperature for $10 \mathrm{~min}$. Finally, the cell suspension was centrifuged; the cellular pellet was suspended in PBS, and samples were analyzed by Epi-fluorescence microscopy (Model E 600, Nikon, Tokio, Japan) with a high-pressure mercury lamp (Model HB-10104AF, Nikon) and filter cube (or optical block) blue excitation filter combination (Model B-2A, Nikon) with spectral profiles as follows: Excitation (EX) filter 450-490 nm, Dichroic Mirror (DM) filter $505 \mathrm{~nm}$, Barrier (BA) filter $520 \mathrm{~nm}$. The cells that stained red were considered as non-viable. 


\subsubsection{Measurement of Cellular Leakage}

Aliquots of $3 \mathrm{~mL}$ of cell cultures exposed to different pressure-time regimes were filtered through a 25-mm-diameter, 0.22- $\mu \mathrm{m}$ pore size Millex-GS syringe filter (Millex-GS, Millipore Co, Billerica, MA, USA), and the presence of nucleic acids and proteins in the cell-free filtrate was checked by measuring the absorbance at $260 \mathrm{~nm}$ and $280 \mathrm{~nm}$, respectively (Beckman DU 7400 Spectrophotometer, Beckman Coulter, Inc., Brea, CA, USA), as described elsewhere [26].

\subsection{Transmission Electron Microscopy (TEM) Analyses}

E. coli cells exposed to 300 and $600 \mathrm{MPa}$ for $5 \mathrm{~min}$ were harvested by centrifugation and fixed in 2.5\% glutaraldehyde (TAAB Laboratories Ltd., Aldermaston, Berks, UK)-PBS for $3 \mathrm{~h}$ at $4{ }^{\circ} \mathrm{C}$. Bacteria were then washed three times with PBS, and cells were treated with osmium tetroxide (TAAB Laboratories)-1\% PBS for $45 \mathrm{~min}$ at room temperature in darkness. Afterwards, three new washings with PBS were performed. Subsequently, cells were pelleted in bacteriological agar (Oxoid, Hampshire, UK), and pellets were dehydrated in ethanol solutions of increasing concentrations and embedded in an epoxy resin (Epon 812; Tousimis, Rockville, MD, USA), which was polarized by its incubation for $48 \mathrm{~h}$ at $60{ }^{\circ} \mathrm{C}$. Finally, ultrathin sections were collected onto copper grids and stained with uranyl and lead. Microscopic observations were carried out on at least ten different microscope fields per treatment condition, using several microscope magnifications of a JEOL 1010 microscope (JEOL Ltd., Tokio, Japan) at $80 \mathrm{kV}$ [26].

\subsection{Fourier Transform Infrared (FTIR) Spectroscopic Analyses}

Control cells and cells exposed to 50,300, 600 and $900 \mathrm{MPa}$ were harvested by centrifugation and suspended in $50 \mu \mathrm{L}$ of PBS, placed $(15 \mu \mathrm{L})$ in a $\mathrm{ZnSe}$ window and stove dried $\left(15 \mathrm{~min}, 50{ }^{\circ} \mathrm{C}\right)$. Infrared spectra were obtained with a FTIR spectroscope (Perkin-Elmer 2000 FTIR, Massachusetts, MA, USA) equipped with a Deuterated Triglycerine Sulfate (DTGS) detector. Measurements were recorded over the wavelength range of 4000 to $700 \mathrm{~cm}^{-1}$ with an interval of $1 \mathrm{~cm}^{-1}$. The spectral resolution was $4 \mathrm{~cm}^{-1}$. The final spectra were achieved averaging 20 scans. FTIR experiments were performed in triplicate. A software application developed for the Perkin-Elmer environment was used for transformation, including normalization ( 0 setting with absorption at $1800 \mathrm{~cm}^{-1}$; 1 setting at maximal absorption, located around $1650 \mathrm{~cm}^{-1}$ ), smoothing and second derivative. After transformation, spectra were recorded in ASCII format and processed [31]. The whole spectrum was divided for calculation purposes into five spectral windows: the window between 3000 and $2800 \mathrm{~cm}^{-1}$, influenced by functional groups of membrane fatty acids (w1); the window between 1800 and $1500 \mathrm{~cm}^{-1}$, affected by amide I and amide II groups belonging to proteins and peptides (w2); the window between 1500 and $1200 \mathrm{~cm}^{-1}$, mixed region influenced by proteins, fatty acids and phosphate-carrying compounds (w3); the window between 1200 and $900 \mathrm{~cm}^{-1}$, which is informative mostly for the carbohydrates and polysaccharides in the cell wall (w4); and the window between 900 and $700 \mathrm{~cm}^{-1}$, named the true fingerprint, because of very specific spectral patterns (w5).

To study variability between replicates and within windows, samples were processed, in independent experiments, yielding three replicates for each HHP treatment condition. The differentiation index 
(DI) [32] was calculated for each pair of the IR spectra, for the working IR range (3000-2800; $1800-700 \mathrm{~cm}^{-1}$ ) and independently for the ranges described (w1 - w5), according to the equations.

$$
r_{y 1 y 2}=\frac{D I_{y 1 y 2}=\left(1-r_{y 1 y 2}\right) \times 1000}{\sqrt{\sum_{i=1}^{n} y 1_{i} y 2_{i}^{2}-n \overline{y 1}} \sqrt{\sum_{i=1}^{n} y 2_{i}^{2}-n \overline{y 2}^{2}}}
$$

where $r_{y 1 y 2}$ is the Pearson's correlation coefficient, $y 1_{i}$ and $y 2_{i}$ are the individual absorbance values of the two spectra to be compared, $n$ is the number of data points in the given range and $\overline{y 1}$ and $\overline{y 2}$ are the arithmetic mean values of $y 1$ and $y 2$.

The three replicates for each combination $(1-2 ; 1-3 ; 1-3)$ are considered and the mean is obtained. DI may adopt values between zero and 2,000, with zero for identical spectra, 1000 for completely non-correlated and 2000 for completely negatively non-correlated spectra [32].

The spectral data were subjected to multivariate statistical methods (Hierarchical Cluster Analysis (HCA) and Factor Analysis (FA)). Pearson's product moment correlation coefficient was used to measure the similarity between spectra, and strain clustering was achieved using Ward's algorithm. All of the analyses (calculation of coefficients, joining of variables, canonical analysis and graphical display) were carried out with the Statistica for Windows, v. 7.0, program (Statsoft Inc., Tulsa, OK, USA).

\section{Conclusions}

Our findings evidence that while exposure of E. coli cells to HHP causes alterations in their physical integrity, with cellular enlargement, membrane damage or detachment, DNA and protein denaturation and leakage of intracellular contents, minor changes in molecular composition are evident, and these are focused in the carbohydrates and polysaccharides of the cell wall. These observations serve to enhance the currently-available knowledge on the mechanisms of bacterial inactivation by HHP and may be valuable to design more effective food preservation regimes based on the integration of mild HHP into a multi-target hurdle technology concept. For instance, our results show that HHP compromises membrane integrity, which suggests that mild HHP might increase the efficacy of food-grade antimicrobials, such as nisin, or other natural antimicrobials that otherwise might be unable to enter the cell.

\section{Acknowledgments}

The authors wish to acknowledge the financial contribution of the Spanish Instituto Nacional de Investigación y Tecnología Agraria (Plan Nacional de Investigación, Desarrollo e Innovación, Ref. RTA2011-00079-C02-02). Strains were kindly provided by O. Alvseike (Norwegian Meat and Poultry Research Center, Oslo, Norway). A. Alvarez-Ordóñez is a Starting Investigator Research Fellow funded by Science Foundation Ireland (SFI) under Grant Number 13/SIRG/2157. 


\section{Author Contributions}

M.P.C., M.P., M.L. and A.A.O. designed the experiments. M.P.C. and A.A.O. carried out the experiments. M.P. and M.L. contributed with materials and reagents. M.P.C., M.P. and A.A.O. wrote the manuscript.

\section{Conflicts of Interest}

The authors declare no conflict of interest.

\section{References}

1. Considine, K.M.; Kelly, A.L.; Fitzgerald, G.F.; Hill, C.; Sleator, R.D. High pressure processing-Effects on microbial food safety and food quality. FEMS Microbiol. Lett. 2008, 281, $1-9$.

2. Kovac, K.; Diez-Valcarce, M.; Hernández, M.; Raspor, P.; Rodríguez-Lázaro, D. High hydrostatic pressure as emergent technology for the elimination of foodborne viruses. Trends Food Sci. Technol. 2010, 21, 558-568.

3. Rendueles, E.; Omer, M.K.; Alvseike, O.; Alonso-Calleja, C.; Capita, R.; Prieto, M. Microbiological food safety assessment of high hydrostatic pressure processing. LWT Food Sci. Technol. 2011, 44, 1251-1260.

4. Omer, M.K.; Alvseike, O.; Holck, A.; Axelsson, L.; Prieto, M.; Skjerve, E.; Heir, E. The application of High Pressure Processing to reduce pathogenic Escherichia coli in Norwegian dry-fermented sausages. Meat Sci. 2010, 86, 1005-1009.

5. European Food Safety Authority (EFSA). The European Union Summary Report on Trends and Sources of Zoonoses, Zoonotic Agents and Food-borne Outbreaks in 2012. EFSA J. 2014, 12, 3547.

6. Alpas, H.; Kalchayanand, N.; Bozoglu, F.; Sikes, A.; Dunne, C.P.; Ray, B. Variation in Resistance to Hydrostatic Pressure among Strains of Food-Borne Pathogens. Appl. Environ. Microbiol. 1999, $65,4248-4251$.

7. Benito, A.; Ventoura, G.; Casadei, M.; Robindon, T.; Mackey, B.M. Variation in resistance of natural isolates of Escherichia coli $\mathrm{O} 157$ to high hydrostatic pressure, mild heat and other stresses. Appl. Environ. Microbiol. 1999, 65, 1564-1569.

8. Robey, M.; Benito, A.; Hutson, R.H.; Pascual, C.; Park, S.F.; Mackey, B.M. Variation in resistance to high hydrostatic pressure and rpoS heterogeneity in natural isolates of Escherichia coli $\mathrm{O} 157: \mathrm{H} 7$. Appl. Environ. Microbiol. 2001, 67, 4901-4907.

9. Álvarez-Ordóñez, A.; Alvseike, O.; Omer, M.K.; Heir, E.; Axelsson, L.; Holck, A.; Prieto, M. Heterogeneity in resistance to food-related stresses and biofilm formation ability among verocytotoxigenic Escherichia coli strains. Int. J. Food Microbiol. 2013, 161, 220-230.

10. Mañas, P.; Pagán, R. Microbial inactivation by new technologies of food preservation. J. Appl. Microbiol. 2005, 98, 1387-1399.

11. Pagán, R.; Mackey, B. Relationship between membrane damage and cells death in pressure-treated Escherichia coli cells: differences between exponential- and stationary- phase cells and variation among strains. Appl. Environ. Microbiol. 2000, 66, 2829-2834. 
12. Ganzle, M.G.; Vogel, R.F. On-line fluorescence determination of pressure mediated outer membrane damage in Escherichia coli. Syst. Appl. Microbiol. 2001, 24, 477-485.

13. Mañas, P.; Mackey, B.M. Morphological and physiological changes induced by high hydrostatic pressure in exponential- and stationary- phase cells of Escherichia coli: Relationship with cells death. Appl. Environ. Microbiol. 2004, 70, 1545-1554.

14. Klotz, B.; Mañas, P.; Mackey, B.M. The relationship between membrane damage, release of protein and loss of viability in Escherichia coli exposed to high hydrostatic pressure. Int. J. Food Microbiol. 2010, 137, 214-220.

15. Smelt, J.P.P.M.; Rijke, A.G.F.; Hayhurst, A. Possible mechanism of high-pressure inactivation of microorganisms. High Press. Res. 1994, 12, 199-203.

16. Wouters, P.C.; Glaasker, E.; Smelt, J.P.P.M. Effects of high pressure on inactivation kinetics and events related to proton efflux in Lactobacillus plantarum. Appl. Environ. Microbiol. 1998, 64, 509-514.

17. Niven, G.W.; Miles, C.C.; Mackey, B.M. The effects of hydrostatic pressure on ribosome conformation in Escherichia coli: An in vivo study using differential scanning calorimetry. Microbiology 1999, 145, 419-425.

18. Ulmer, H.M.; Herberhold, H.; Fahsel, S.; Ganzle, M.G.; Winter, R.; Vogel, R.F. Effect of pressure-induced membrane phase transitions on inactivation of HorA, an ATP-dependent multidrug resistance transporter, in Lactobacillus plantarum. Appl. Environ. Microbiol. 2002, 68, 1088-1095.

19. Mackey, B.M.; Mañas, P. Inactivation of Escherichia coli by high pressure. In High Pressure Microbiology; Michiels, C., Aertsen, A., Bartlett, D., Yayanos, Y., Eds.; ASM Press: Washington, DC, USA, 2008; pp. 53-85.

20. Mackey, B.M.; Forestiere, N.S.; Isaacs, N.S.; Stenning, R.; Brooker, B. The effect of high hydrostatic pressure on Salmonella Thompson and Listeria monocytogenes examined by electron microscopy. Lett. Appl. Microbiol. 1994, 19, 429-432.

21. Park, S.W.; Sohn, K.H.; Shin, J.H.; Lee, H.J. High hydrostatic pressure inactivation of Lactobacillus viridescens and its effects on ultrastructure of cells. Int. J. Food Sci. Technol. 2001, 36, 775-781.

22. Kaletunc, G.; Lee, J.; Alpas, H.; Bozoglu, F. Evaluation of structural changes induced by high hydrostatic pressure in Leuconostoc mesenteroides. Appl. Environ. Microbiol. 2004, 70, 1116-1122.

23. Álvarez-Ordóñez, A.; Mouwen, D.J.M.; López, M.; Prieto, M. Fourier transform infrared spectroscopy as a tool to characterize molecular composition and stress response in foodborne pathogenic bacteria. J. Microbiol. Methnol. 2011, 84, 369-378.

24. Álvarez-Ordóñez, A.; Prieto, M. Fourier Transform Infrared Spectroscopy in Food Microbiology; Springer: New York, NY, USA, 2012.

25. Ward, J.H., Jr. Hierarchical grouping to optimize an objective function. J. Am. Stat. Assoc. 1963, $58,236-244$.

26. Álvarez-Ordóñez, A.; Prieto, M. Changes in ultrastructure and Fourier transform infrared spectrum of Salmonella enterica serovar Typhimurium cells after exposure to stress conditions. Appl. Environ. Microbiol. 2010, 76, 7598-7607.

27. Álvarez-Ordóñez, A.; Carvajal, A.; Arguello, H.; Martínez-Lobo, F.J.; Naharro, G.; Rubio, P. Antibacterial activity and mode of action of a commercial citrus fruit extract. J. Appl. Microbiol. 2013, 115, 50-60. 
28. Al-Qadiri, H.M.; Al-Alami, N.I.; Al-Holy, M.A.; Rasco, B.A. Using Fourier Transform Infrared (FTIR) absorbance spectroscopy and multivariate analysis to study the effect of chlorine-induced bacterial injury in water. J. Agric. Food Chem. 2008, 56, 8992-8997.

29. Hu, X.; Qiu, Z.; Wang, Y.; She, Z.; Qian, G.; Ren, Z. Effect of ultra-strong static magnetic field on bacteria: Application of Fourier-transform infrared spectroscopy combined with cluster analysis and deconvolution. Bioelectromagnetics 2009, 30, 500-507.

30. Sartz, L.; de Jong, B.; Hjertqvist, M.; Plym-Forshell, L.; Alsterlund, R.; Lofdahl, S.; Osterman, B.; Stahl, A.; Eriksson, E.; Hansson, H.; et al. An outbreak of Escherichia coli O157:H7 infection in southern Sweden associated with consumption of fermented sausage; aspects of sausage production that increase the risk of contamination. Epidemiol. Infect. 2008, 136, 370-380.

31. Mouwen, D.J.M.; Weijtens, M.J.B.M.; Capita, R.; Alonso-Calleja, C.; Prieto, M. Discrimination of enterobacterial repetitive intergenic consensus PCR types of Campylobacter coli and Campylobacter jejuni by Fourier transform infrared spectroscopy. Appl. Environ. Microbiol. 2005, 71, 4318-4324.

32. Naumann, D. Infrared spectroscopy in microbiology. In Encyclopedia of Analytical Chemistry; Meyers, R.A., Ed.; John Wiley \& Sons Ltd: Chichester, UK, 2000; pp. 102-131.

Sample Availability: Samples of the two E. coli strainsare available from the authors.

(C) 2014 by the authors; licensee MDPI, Basel, Switzerland. This article is an open access article distributed under the terms and conditions of the Creative Commons Attribution license (http://creativecommons.org/licenses/by/4.0/). 